\title{
Performance Improvement of Active Power Filter using a New Control Strategy under Unbalanced Grid Voltage
}

\author{
Mouna Tali1, Tamou Nasser2 and Ahmed Essadki 3 \\ 1 Laboratory :Electrical Engineering University Mohamed 5 \\ Rabat, Morocco \\ 2 Electronic Communication networks Department ENSIAS Mohamed V University \\ Rabat, Morocco \\ 3 Laboratory :Electrical Engineering University Mohamed 5 \\ Rabat, Morocco
}

\begin{abstract}
In this paper, the active power filter is discussed and proposed in order to improve power quality. It has been proved to be an efficient way to compensate harmonic currents and reactive power generated by nonlinear loads which affect and degrade the power quality under any voltage conditions: balanced and unbalanced condition. The APF proposed in this paper uses a new approach of detecting compensation currents using mixed coordinates and also uses a new control for VDC regulation. This method is proposed for simplicity of the control circuit of the active power filter. To verify the effective performance of the proposed method, simulations are presented in Matlab /Simulink. Keywords: shunt active power filter, Total Harmonic Distortion THD and Non Linear Load.
\end{abstract}

\section{Introduction}

In an ideal case of power application, the electric system should be operated with better power quality and higher efficiency. Thus, the voltage and current must be sinusoidal, in phase and balanced this without harmonics and reactive power. However, in practical power applications, nonlinear loads are widely used [1][2][3]. This process causes pollution and serious damage; therefore, distorted current and reactive power would exist. Electrical machines, transformers, variable speed drives, computers, measuring instruments, consumer appliances are mostly affected by harmonics. Hence, it is very important to overcome these undesirable features. Different approaches of power filters have been developed to improve power quality like shunt passive filters, which comprised of tuned LC elements. It was popular solution for harmonics mitigation because it has some advantages such as simplicity, reliability and cost. But this type of filter, has two major limitations, on the one hand, each filter is only effective for one harmonic of a definite frequency, [4][10] on the other hand, resonance may occur with the impedance grid which would create other harmonics. To overcome these limitations Active power filter appears to be a viable solution for mitigate harmonics and compensate reactive power [5][6][7]. The active power topology can be connected in series for compensation of voltage harmonic compensation, and in parallel for compensation of current harmonic compensation or combination of both (unified power quality conditioners UPQC). Most of the industrial applications need current harmonic compensation so the shunt active filter is more popular than series active filter.[8,9,11,12] Different approaches have been proposed and implemented for extracting the harmonic current, such as the instantaneous power theory developed and defined by Akagi in 1984 based in three phase three wires. This theory gives good performance for balanced supply condition; however, when the voltage source is significantly unbalanced, performance is poor, $[13,14,15,16]$ and it was later modified and extended by Nabae and applicable to the 4 wires, unbalanced systems (modified PQ theory or PQR theory). Other researchers use synchronous reference frequency noted dq theory. This method is ideally designed for 3 phases but the use of PLL is necessary, it was also modified and named modified SRFT or id-iq method without using PLL. [17, 18, 19, 20].There are various other control techniques based on fuzzy logic, neural network and genetic algorithm which have been used for improving the performance of the active filter.

\section{Shunt Active Filter}

The SAPF is basically a voltage-source inverter with only a single capacitor in the DC side, it is connected in parallel with the nonlinear to detect and inject compensating harmonics at the PCC which have the same magnitude but opposite in phase of the harmonic currents drawn by the nonlinear loads. As a result, the source current can be balanced and sinusoidal in phase with supply voltage, but the load currents of nonlinear load are still unbalanced, non-sinusoidal and with harmonics. The proposed Shunt Active Power Filter in this work is shown in fig.1. The 
considered load to evaluate the effectiveness of the proposed scheme is three phase rectifier with R-L load.

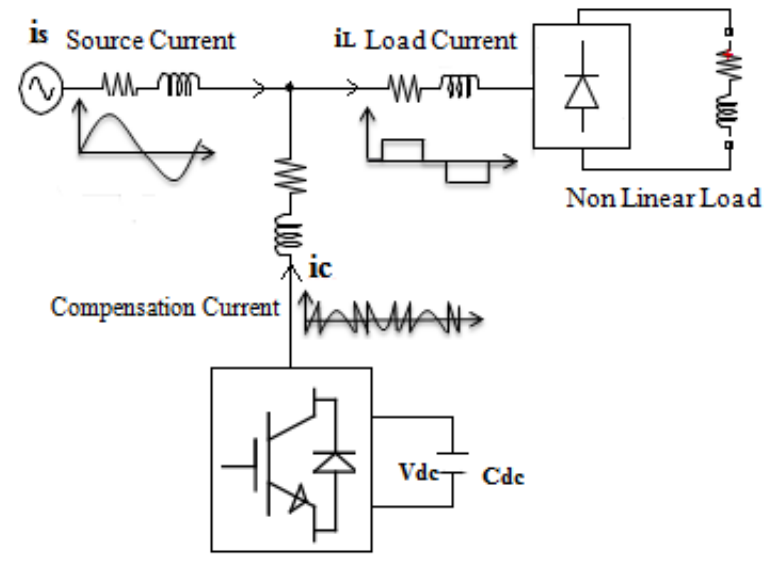

Fig.1. Shunt Active Filter

\subsection{Current Reference Generation}

Using a proper method for current reference generation is the key to successful implementation of SAPF compensation. In this paper, the basic idea is to calculate the reference current on mixed coordinates abc frames and $\alpha \beta 0$ frames using the instantaneous power theory in the time domain. First, the instantaneous active power is defined on abc coordinates, it is consisting of DC component and oscillating component which are separated through a Low Pass filter, after the average equivalent admittance of the nonlinear load ( $\overline{\mathrm{Ge}})$ is calculated by equation 24. Hence, the instantaneous active portions of the load current are directly obtained in $\alpha \beta 0$ coordinates by multiplying $(\overline{\mathrm{Ge}})$ with the voltages $\mathrm{V} \alpha, \mathrm{V} \beta$ and $\mathrm{V} 0$ respectively. Finally, with inverse Clarke transformation, the final instantaneous compensating current for abc coordinates is shown in equation 22 .

The instantaneous active power $\mathrm{p}$ and reactive power $\mathrm{q}$ in three phase system can be expressed by:

$$
\begin{aligned}
& p=\vec{v}_{a b c} \cdot \vec{i}_{a b c} \\
& q=\vec{v} \times \vec{i} \\
& p=v_{a} i_{a}+v_{b} i_{b}+v_{c} i_{c}
\end{aligned}
$$

The instantaneous reactive power vector composed of three elements $\mathrm{q}_{\mathrm{a}}, \mathrm{q}_{\mathrm{b}}$ and $\mathrm{q}_{\mathrm{c}}$ as follows:

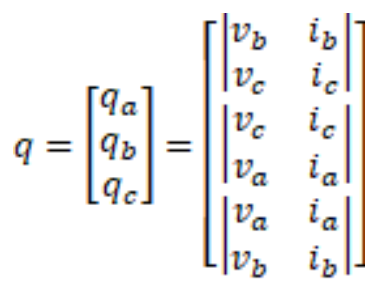

The instantaneous powers defined above are combined in a matrix expression as follows:

$$
\left[\begin{array}{l}
p \\
q_{a} \\
q_{b} \\
q_{c}
\end{array}\right]=\left[\begin{array}{lcc}
v_{a} & v_{b} & v_{c} \\
0 & -v_{c} & v_{b} \\
v_{c} & 0 & -v_{b} \\
-v_{b} & v_{a} & 0
\end{array}\right] \cdot\left[\begin{array}{c}
i_{a} \\
i_{b} \\
i_{c}
\end{array}\right]
$$

The currents can be expressed by the inverse transformation of (5) as follows:

$$
\left[\begin{array}{l}
i_{a} \\
i_{b} \\
i_{c}
\end{array}\right]=\frac{1}{v_{a b c}^{a}}\left[\begin{array}{cccc}
v_{a} & 0 & v_{c} & -v_{b} \\
v_{b} & -v_{c} & 0 & v_{a} \\
v_{c} & v_{b} & -v_{a} & 0
\end{array}\right] \cdot\left[\begin{array}{l}
p \\
q_{a} \\
q_{b} \\
q_{c}
\end{array}\right]
$$

$$
\text { Where: } v_{a b c}^{2}=\Delta=v_{a}^{2}+v_{b}^{2}+v_{c}^{2}
$$

From (6), active and reactive current component can be derived as follows:

$$
\begin{gathered}
\vec{l}_{p}=\left[\begin{array}{l}
i_{a p} \\
i_{b p} \\
i_{c p}
\end{array}\right]=\left[\begin{array}{c}
\frac{v_{a p}}{v_{a b c}^{a}} \\
\frac{v_{b} p}{v_{a b c}^{a}} \\
\frac{v_{c} p}{v_{a b c}^{a}}
\end{array}\right] \\
\vec{i}_{q}=\left[\begin{array}{l}
i_{a q} \\
i_{b q} \\
i_{c q}
\end{array}\right]=\frac{1}{v_{a b c}^{a}} \cdot\left[\begin{array}{cc}
v_{c} q_{b} & -v_{b} q_{c} \\
-v_{c} q_{a} & v_{a} q_{c} \\
v_{b} q_{a} & -v_{a} q_{b}
\end{array}\right]
\end{gathered}
$$

The instantaneous active current vector $\overrightarrow{\vec{i}_{p}}$ and the instantaneous reactive current vector $\vec{i}_{q}$ are expressed as:

$$
\begin{aligned}
& \vec{l}_{p}=\frac{p}{\vec{v}_{a b b} \vec{v}_{a b c}} \cdot \vec{v}_{a b c} \\
& \vec{\imath}_{q}=\frac{\vec{q} \times \vec{v}_{a b c}}{\vec{v}_{a b c} \vec{v}_{a b c}}
\end{aligned}
$$


The abc imaginary currents correspond to the components in the original currents $i_{a}, i_{b}$, $i_{c}$, which generate only imaginary power as follows:

$$
\begin{aligned}
& i_{a q}=\frac{v_{c}}{\Delta} q_{b}-\frac{v_{b}}{\Delta} q_{c} \\
& i_{b q}=\frac{v_{a}}{\Delta} q_{c}-\frac{v_{c}}{\Delta} q_{a} \\
& i_{c q}=\frac{v_{b}}{\Delta} q_{a}-\frac{v_{a}}{\Delta} q_{b}
\end{aligned}
$$

Where:

$$
\begin{aligned}
& q_{a}=v_{b}, i_{c}-v_{c}, i_{b} \\
& q_{b}=v_{c} \cdot i_{a}-v_{a} \cdot i_{c} \\
& q_{c}=v_{a} \cdot i_{b}-v_{b} \cdot i_{a}
\end{aligned}
$$

Finally, the instantaneous compensating reactive current can be described by:

$i_{a q}=\frac{v_{c}}{\Delta} \cdot v_{c}, i_{a}-\frac{v_{c}}{\Delta} \cdot v_{a}, i_{c}-\frac{v_{b}}{\Delta} \cdot v_{a}, i_{b}+\frac{v_{b}^{a}}{\Delta}, i_{a}$

After simplification, the instantaneous compensating reactive current in phase (a) can be obtained as given in (18).

$$
i_{a q}=\frac{1}{\Delta}\left(i_{a}, \Delta-v_{a} p\right)
$$

The final instantaneous compensating current $\overrightarrow{t_{c}^{*}}$ is composed of instantaneous active and reactive current as shown in (22):

$$
\overrightarrow{l_{c}^{*}}=\vec{i}_{c p}+\vec{i}_{c q}
$$

Where:

$$
\begin{aligned}
& i_{c p}=\frac{v_{a} \hat{p}}{\Delta} \\
& i_{a c}^{*}=i_{a}-\frac{v_{a} \bar{p}}{\Delta}
\end{aligned}
$$

The final instantaneous current for abc coordinates is shown in:

$$
i_{c}^{*}=\left|\begin{array}{l}
i_{a}-\frac{\bar{p}}{\Delta} v_{a} \\
i_{b}-\frac{\bar{p}}{\Delta} v_{b} \\
i_{c}-\frac{\vec{p}}{\Delta} v_{c}
\end{array}\right|
$$

Moreover, the voltage and current vectors can also be expressed in $\alpha \beta 0$ frame, and then the compensating current can be described by:

$$
i_{c}^{*}=\left|\begin{array}{l}
i_{\sigma}-\frac{\bar{p}}{\Delta} v_{\alpha \sigma} \\
i_{\beta}-\frac{\bar{p}}{\Delta} v_{\beta} \\
i_{0}-\frac{\bar{p}}{\Delta} v_{0}
\end{array}\right|=\left|\begin{array}{l}
i_{\alpha}-\bar{G}_{e} v_{\alpha \varepsilon} \\
i_{\beta}-\bar{G}_{e} v_{\beta} \\
i_{0}-\bar{G}_{e} v_{0}
\end{array}\right|
$$

Where:

$$
\bar{G}_{e}=\frac{\bar{p}}{\Delta}
$$

Where: $p=v_{a}, i_{a}+v_{b}, i_{b}+v_{c}, i_{c}$ and $\bar{p}$ is the average value of $p$.

The proposed algorithm in mixed coordinates $\alpha \beta 0$ and abc for compensating the nonlinear loads currents and reactive power is depicted in figure. 2 .

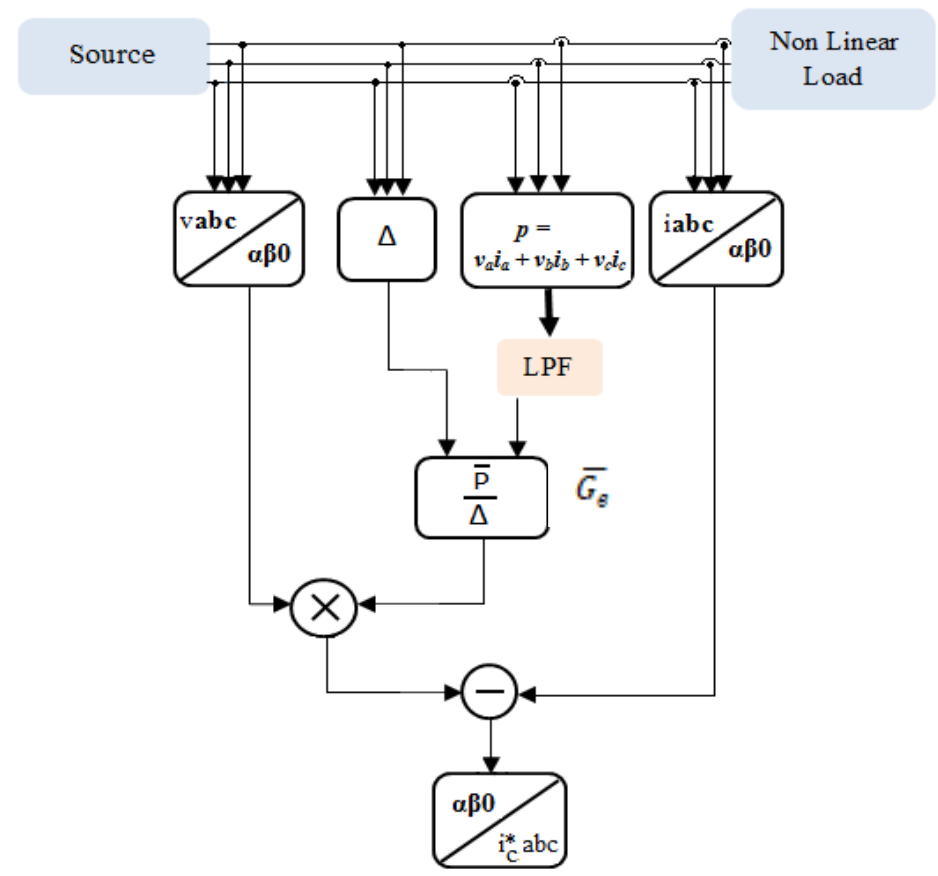

Fig. 2 the mixed coordinates instantaneous compensation algorithm 
The compensating currents and injecting currents at PCC are compared to generate PWM pulses in order to command VSI (voltage source inverters) switches as shown in figure 3 .

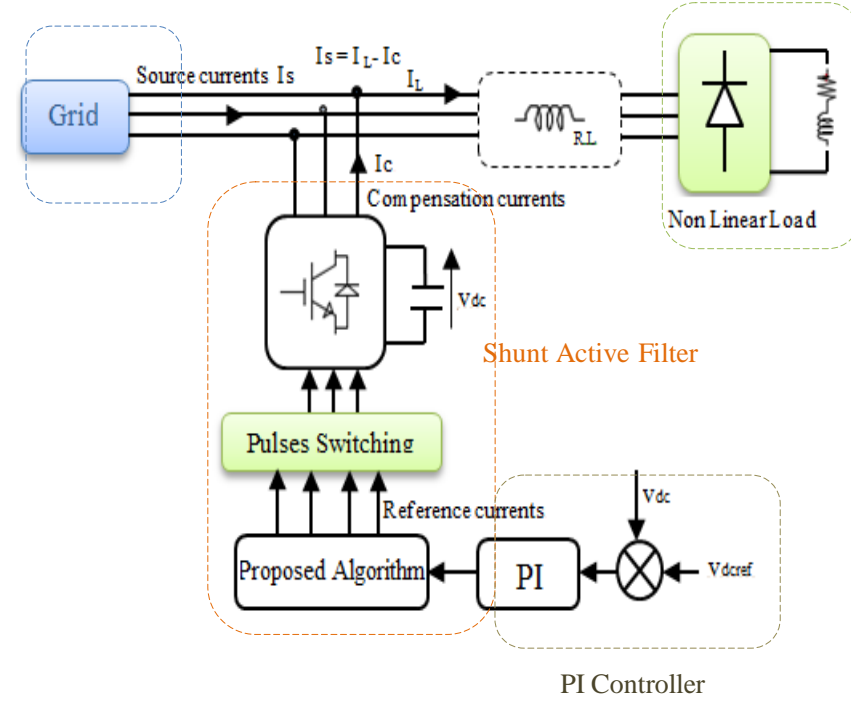

Fig.3.Basic structure of Shunt Active Power Filter

\subsection{Voltage Regulator}

To guarantee a better compensation, the voltage across DC capacitor should be maintained at the prescribed reference. The DC capacitor voltage plays two important roles in APF control, first it maintains a dc voltage with small ripple in steady state, and second it serves as energy balancing medium that supplies or absorbs real power at times of transient period. Therefore, the peak value of reference current of the system under compensation is related to value of DC voltage, the regulator regulates this voltage to a fixed value; it also gives the command for calculation of peak value of reference current. A classic PI controller can be used vastly for this purpose. In regulation scheme involving PI controller, the capacitor voltage is compared with reference value of DC voltage. The error signal is then processed through a PI controller, the output of the PI controller is considered as peak value of the current, which accounts for losses in the APF to maintain the average capacitor voltage to a constant value.

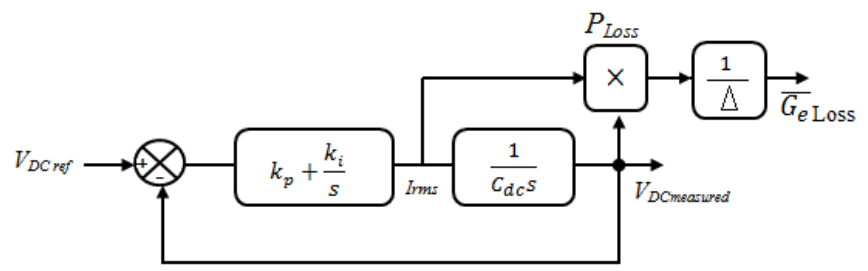

Fig.4. DC voltage regulator

The $\mathrm{P}_{\text {Loss }}$ can be calculated as in the following equation:

$$
\begin{gathered}
P_{\text {Loss }}=\Delta V_{D C}\left(k_{p}+\frac{k_{\mathrm{i}}^{\tilde{i}}}{\sigma}\right) \times V_{D \text { Cmeasured }} \\
\bar{G}_{\text {eLoss }}=\frac{\bar{p}_{\text {Loss }}}{\Delta}
\end{gathered}
$$

The transfer function of voltage control loop is:

$$
\frac{V_{D \text { Cmens }}}{V_{\text {DCref }}}=\frac{\omega_{c}^{2}(1+\tau s)}{s^{2}+2 s_{c} \omega_{c} s+\omega_{c}^{2}}
$$

Where:

$$
\omega_{c}=\sqrt{\frac{k_{i}}{c}} \quad \varepsilon_{c}=\frac{1}{2} \frac{k_{p}}{\sqrt{c k_{i}}}
$$

To have a good regulation we have chosen $\xi_{\mathrm{c}}=0.7$, but the cutoff frequency should be selected according to the harmonics of the loop voltage.

\section{Simulation Results :}

To verify the performance of the proposed compensation algorithm for the SAPF, results obtained by using Matlab/Simulink are given. In the first case, balanced sinusoidal source voltage condition has been considered; figure 5 shows the simulated result of the source currents before and after compensation with mixed coordinates instantaneous compensation algorithm. Without filter, it can be observed that source currents are distorted and with harmonics; as a result, the percentage of THD exceeds above IEEE-519 standard harmonic current limits. Figure 7 shows harmonic spectrum where total harmonic distortion is found to be $22.12 \%$. At $\mathrm{t}=0.04 \mathrm{~s}$, with filter implementation, it can be clearly seen that the SAPF follows the reference currents to compensate the harmonic currents and reactive power, so source currents are sinusoidal and balanced. The THD is restricted as per IEEE-519 to $2.59 \%$. In the second case, source voltages 
are unbalanced in magnitude. The magnitude of source voltage of phase-a- is less than source voltage of phase-band phase $-\mathrm{c}$ - by $20 \%$. Simulated results are presented in figure 7 , the effect of unbalanced source voltage can be observed in load currents in which the THD is $25.44 \%$. But with the proposed algorithm the best compensation is widely required where source currents are very close to sinusoidal waveforms and in phase with their corresponding source voltages. Power factor is also very close to unity.

\section{- Simulation results in balanced voltages :}
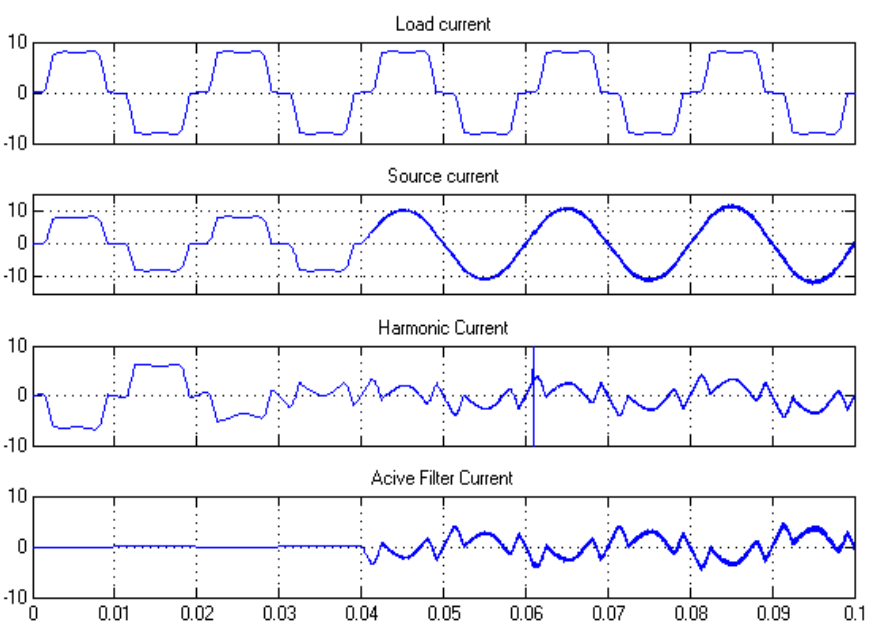

Fig.5. load current, source current, harmonic current and compensation current reference of phase (a).

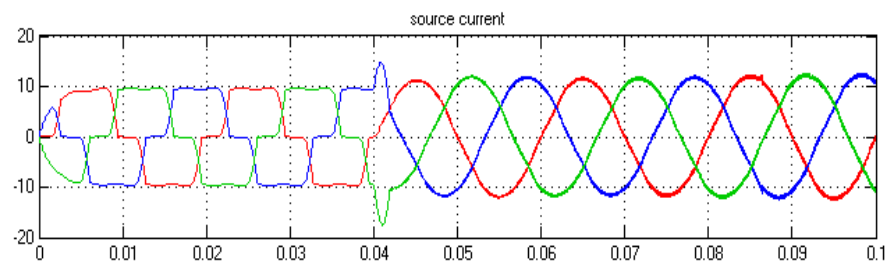

Fig.6. Source currents waveform without and with filter.

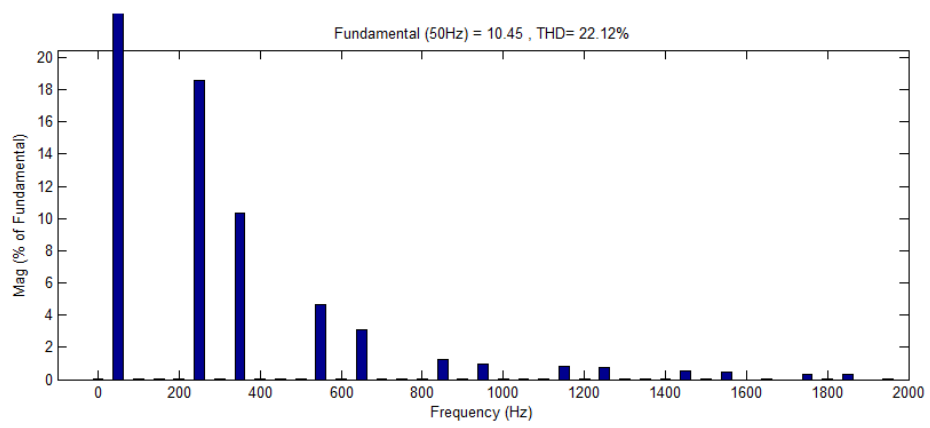

Fig.7 harmonic spectrum source current without APF

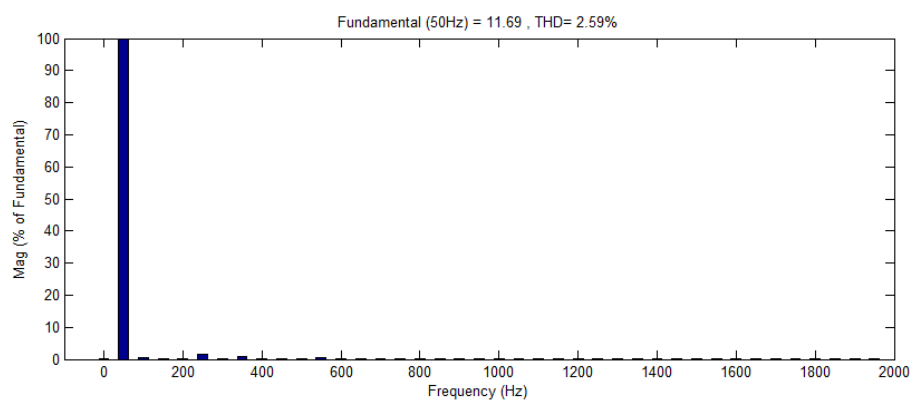

Fig .8.Harmonic spectrum of source current with SAPF

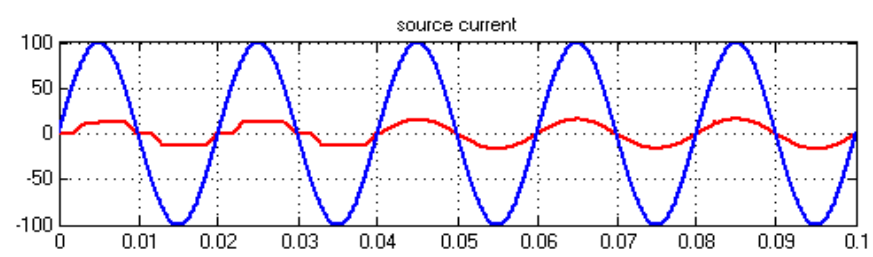

Fig.9. Source current and source voltage waveform

\section{- Simulation results in unbalanced voltages :}

When the phase (a) is unbalanced, the proposed algorithm gives a good compensation of the line current THDisa $=5.13 \%$, THDisb $=3.69 \%$, THDisc $=3.6 \%$. Balance of the source current is well observed in figure .11 .

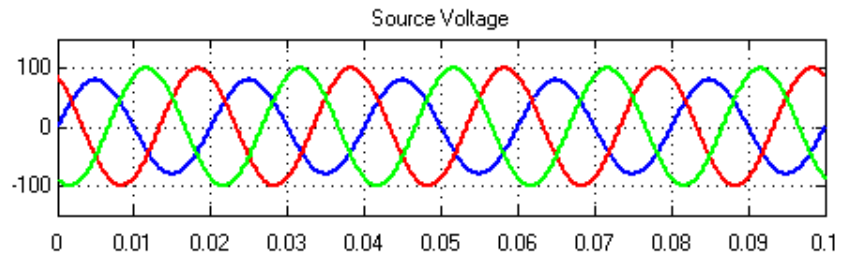

Fig.10.Unbalanced sinusoidal source voltage. 


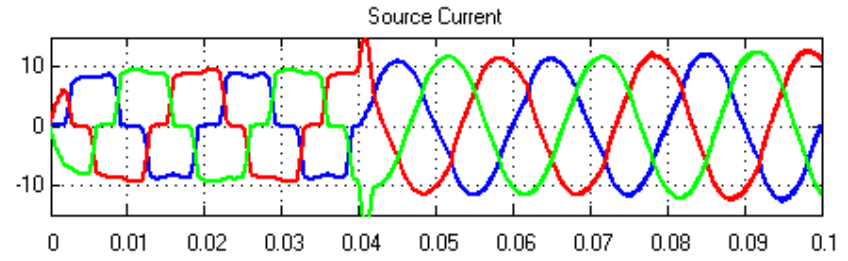

Fig.11. Source current under unbalanced source voltage with and without filter.
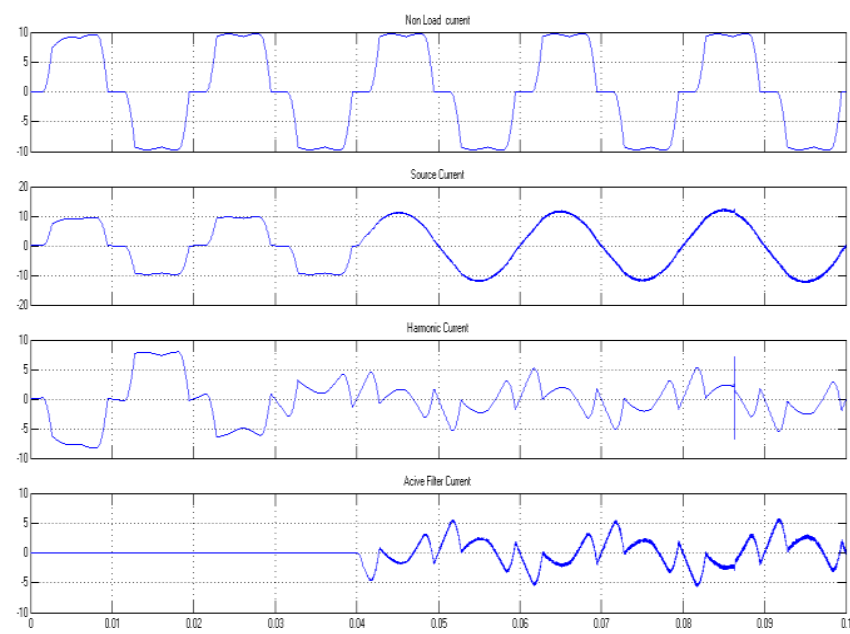

Fig.12. load current, source current, harmonic current and compensation current reference in phase (a) under unbalanced source voltage.

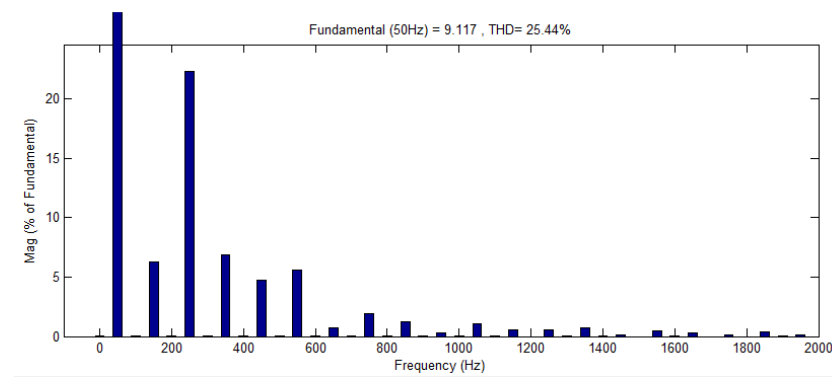

Fig.13. harmonic spectrum source current without APF under unbalanced source voltage.

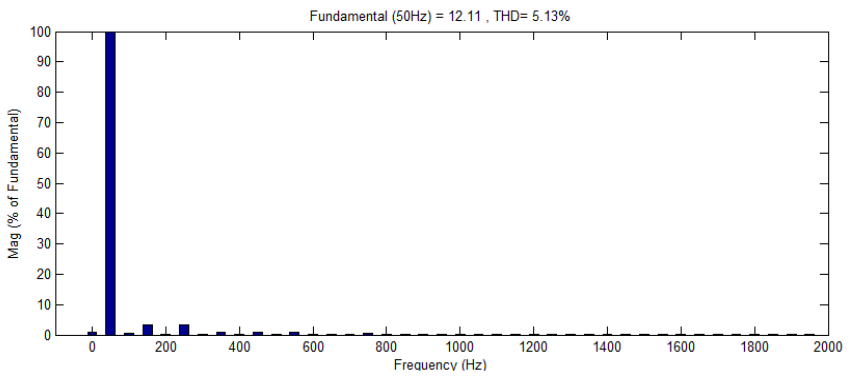

Fig .14.Harmonic spectrum of source current under unbalanced source voltage.

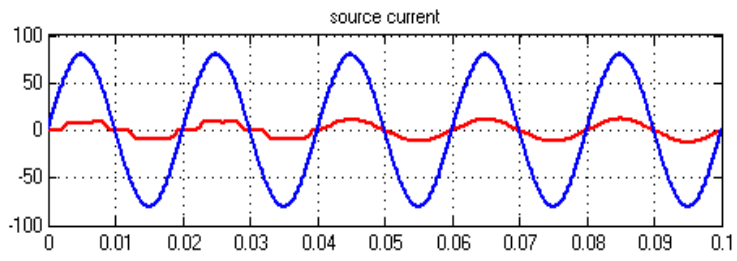

Fig.15. Source current and source voltage waveform under unbalanced source voltage (phase a).

In this condition, as seen in figure 15 the presence of unbalance in the source voltage does not have an effect on the performance of the APF. The source current and the source voltage are balanced and also in phase.

Table 1: Current THD value with and without SAPF

\begin{tabular}{|c|c|c|}
\hline $\begin{array}{c}\text { THD for } \\
\text { Source Current }\end{array}$ & $\begin{array}{c}\text { Balanced } \\
\text { voltage }\end{array}$ & $\begin{array}{c}\text { Unbalanced } \\
\text { voltage }\end{array}$ \\
\hline Without APF & $22.12 \%$ & $25.44 \%$ \\
\hline With APF & $\mathbf{2 . 5 9 \%}$ & $\mathbf{5 . 1 \%}$ \\
\hline
\end{tabular}

The parameters simulation is shown in Table 2 .

Table 2: Parameters used in simulation

\begin{tabular}{|c|c|}
\hline Parameter & Value \\
\hline$V s$ & $100 v-50 \mathrm{~Hz}$ \\
\hline$R_{L} L_{L}$ & $24 \Omega-25 \mathrm{mH}$ \\
\hline$L s$ & $0.3 \mathrm{mH}$ \\
\hline$C d c$ & $1800 \mu \mathrm{F}$ \\
\hline$V d c$ & $900 \mathrm{v}$ \\
\hline$L f$ & $8.3 \mathrm{mH}$ \\
\hline
\end{tabular}

\section{Conclusions}

Most of the algorithms used for APFs degrade performance in the case of voltage unbalanced. This paper presents a new and efficient strategy of SAPF where the reference currents are based on a new algorithm on mixed coordinates. Its performance has been evaluated under source voltages unbalanced, and simulation shows excellent results. The harmonics generated by nonlinear load are eliminated and the reactive power can be compensated. 


\section{References}

[1] Akagi, H., Kanazawa, Y. and Nabae, A. "GeneralizedTheory of the Instantaneous Reactive Power inThree-Phase Circuits", IPEC. Int. Power Electronics Conf, Tokyo, Japan, 1983 pp. 1375-1386.

[2] H. Akagi, Y. Kanazawa, A. Nabae, "Instanataneous Reactive Power Compensator Comprising Switching Devices without Energy Storage Compenents", IEEE vol. 20, 1984.

[3] H. Akagi,T.TANAKA, "Harmonic Power Detection Based On The pq Theory and Its Applications"

[4] S. Rahini, S.A Karthick Kumar, "Performance Evaluation of Shunt Active Harmonic Filter Under Different Control Techniques" ICCPCT, 2015.

[5] A.F.Hanna, Nohra, "A control strategy in activr power filter for power quality improvent", IEEE, ICPERE 978-14996402-4, 2014.

[6] J .Afonso, C.Couton, J.Martins, "Active Filters with control based on the pq theory", IEEE, vol 47, N³, sep 2000 ISSN0746-1240 pp 5-10.

[7] B. Singh, K.Al haddad, "A review of active filter for power quality improvement", IEEE, vol 46, №5, october 1999.

[8] R. Pregitzer, J.G.Pinto, "Parallel Association of shunt active power filters", IEEE, june 4-7spain 2007, 1-4224-07559.

[9] D.R Dobariya, P.A .Upadhyay, "Simulation and comparaison between hybrid active power filter and shunt active power filter", EESCO ,IEEE, 2015.

[10] M. TALI, A. Obbadi, A. Elfajri, Y. Errami , "Passive Filter for harmonics mitigation in standalone pv system for non linear load", Renewable and Sustainable Energy Conference (IRSEC), IEEE, 978-1-4799-7335-4, 2014, pp 499 - 504.

[11] M.Ghandchi, A.Ajami, M.Moeni, "A simple and low cost control strategy for multilevel shunt active filter" oct 14-17, 2008, International conference on control automation and systems Korea.

[12] A.Subramaniya Siva, M. Bhavani "Mitigation of Harmonics by Shunt Active Power Filter Synchronous Detection Method", IJETT, June2013.2231-5381 .

[13] J.Miret, M.Castilla, José Matas "Selective HarmonicComensation Control for Single-Phase Active Power Filter With High Harmonic Rejection", IEEE, 2009, 02780046/26.00.

[14] H. Akagi "New Trends in Active Filters For Power Conditionning", IEEE, vol $32 \mathrm{~N}^{\circ} 6,1996$.

[15] Gary W.Chang, Senior, Tai-Chang Shee "A Novel Reference Compensation Current Strategy for Shunt Active Power Filter Control" IEEE, vol 19, N44, October 2004.

[16] G.W.Chang, S.K.Chen "An a-b-c Reference Frame-Based Control Strategy for the Three-Phase Four-Wire Shunt Active Power Filter", IEEE, 2000.

[17] A. O.Montes, G.Ramos "Instantaneous p-q Theory for harmonic compensation via shunt active power filter", IEEE, 2013, 978-1-4799-1007-6

[18] E.H. Watanabe, M.Aredes, H.Akagi "The P-Q Theory for Active Filter Control: Some Problems And Solutions"

[19] C.Lascu, L.Asiminoaei "High Performance Current Controller for Selective Harmonic Compensation in Active Power Fiters", IEEE.2007.10.1109/TPEL.904060.
[20] A. Boussaid, A.Lokman Nemmour, L.Louze, A.Khezzar "Anovel strategy for shunt active filter control "ELSEVIER, March 2015, 154-163.6.

MOUNA TALI: was born in SAFI, Morocco, she received a License degree from ENSET School, Mohamed 5 Souissi University, Rabat, and DESS degree from university chouaib doukkali, Eljadida in 2005 , she currently working toward the PhD degree in electrical engineering research at ENSET:

TAMOU NASSER: is currently an Associate Professor at the communication networks department of National High school for Computer Science and system (ENSIAS),Mohamed V,Morocco,since 2009, she received her PHD in 2005 and her research MS degree ,in 2000, respectively, all in electrical engineering from Mohamedia Engineering energy, motor drive ,power sytem, and smart grid. Doctor TAMOU NASSER Is a member of $\mathrm{Al}$ jazari research group.

AHMED ESSADKI: is currently a Professor and university research professor at the electrical engineering department of ENSET,Mohamed V Souissi University, Morocco. In $2000 \mathrm{He}$ received hi PHD degree from Mohamedia Engineering SCHOOL (EMI), (Morocco).From 1990 to 1993, he pursued his Mater program at UQTR University, Quebec Canada, respectively, all in electrical engineering, His current research interest include renewable energy, motor drives and power system. Doctor Ahmed ESSADKI is a member of RGE Lab in research group leader. 